\title{
Review
}

\section{Redundant cell death mechanisms as relics and backups}

\author{
P Golstein ${ }^{\star, 1}$ and G Kroemer ${ }^{2}$ \\ 1 Centre d'Immunologie de Marseille-Luminy, CNRS-INSERM-Université de la \\ Mediterranée, Parc Scientifique de Luminy, Case 906, 13288 Marseille cedex \\ 9, France \\ ${ }^{2}$ Centre National de la Recherche Scientifique, UMR8125, Institut Gustave \\ Roussy, 39 rue Calmette Desmoulins, F-94805 Villejuif, France \\ * Corresponding author: P Golstein, Centre d'Immunologie de Marseille-Luminy, \\ CNRS-INSERM-Université de la Mediterranée, Parc Scientifique de Luminy, \\ Case 906, 13288 Marseille cedex 9, France. \\ Tel: + 334912694 68; Fax: + 334912694 30; \\ E-mail: golstein@ ciml.univ-mrs.fr
}

Received 03.12.04; revised 24.1.05; accepted 26.1.05; published online 01.4.05 Edited by EH Baehrecke

\begin{abstract}
Here we review recent observations indicating the existence of redundant cell death mechanisms. We speculate that this redundancy reflects a particular evolutionary history for cellular demise. Autophagic or apoptotic elements might have been added to a primordial death mechanism, initially improving cell dismantling and later acquiring the ability to act themselves as death effectors. The resulting redundancy of cell death mechanisms has pathophysiological implications.

Cell Death and Differentiation (2005) 12, 1490-1496.

doi:10.1038/sj.cdd.4401607; published online 1 April 2005
\end{abstract}

Keywords: cytochrome; apoptosis

Abbreviations: AIF, apoptosis inducing factor; Cyt $c$, cytochrome $c$

\section{Introduction}

While specific cell death pathways have usually been studied as isolated phenomena (as exemplified by the extensive research on caspase-dependent apoptosis), cell death can be considered as a network of elementary mechanisms, acting in series or in parallel, each of which can be variably expressed in different eukaryotic species and, within the same species, among distinct cell types. In the course of evolution, an ancestral cell death mechanism, which may be extant in the form of necrosis, may have become embellished with elements of apoptosis and/or of autophagy, as both represent a selective advantage since they contribute to the elimination of cell corpses. These processes may in turn have become autonomous cell death mechanisms, and in some cases have even gained exclusivity. This evolutionary accumulation of cell death mechanisms may have resulted in the availability of more than one death effector mechanisms within each extant cell, with important implications for the detection and therapeutic manipulation of cell death.

\section{Cell Death Types, Mechanisms and Stages}

Different types of cell death were defined in purely morphological terms, ${ }^{1-4}$ with limited reference to the underlying biochemical changes. Mammalian cells can die from 'apoptosis' (showing nuclear condensation and fragmentation, DNA fragmentation and cytoplasmic condensation), 'necrosis' (generalized swelling of cells and organelles with limited or no chromatin condensation), and 'autophagic cell death' (death with accumulation of autophagosomes and subsequently vacuoles). Several intermediate or mixed cell death types have been reported, such as 'apoptosis-like' cell death with a less pronounced, subapoptotic chromatin condensation, ${ }^{5}$ paraptosis, ${ }^{6}$ oncosis, ${ }^{3}$ necrapoptosis with cytoplasmic vacuolization and pronounced mitochondrial swelling not seen in apoptosis, ${ }^{7}$ and apoptosis with autophagic vacuoliza-

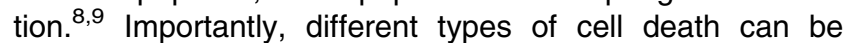
induced in a context-dependent fashion by the very same initiating stimulus, for instance by binding of specific ligands to so-called death receptors anchored in the plasma membrane (Figure 1).

A schematic and simplified view of the molecular mechanisms underlying the main cell death types - in mammalian cells - may be as follows. Apoptosis involves the near-toobligatory activation of caspases, a family of cysteine proteases. Autophagic cell death shows autophagy, namely the sequestration of cytoplasmic organelles in autophagosomes, followed by their fusion with lysosomes, a process that results in the digestion of the luminal content within autophagolysosomes, and requires a series of well-characterized autophagy gene products. ${ }^{10}$ Necrosis is likely to result, at least in part, from severe ATP depletion. ${ }^{11}$

Such cell death pathways can be divided into distinct stages (Figure 1). During the initial signaling stage, cells integrate metabolic stress signals, sense DNA damage, or receive critical information from the extracellular space or from neighboring cells, often through specific cell surface receptors. The subsequent effector stage is marked by the first irreversible biochemical event (also designated as point-ofno-return), after which the removal of the death-inducing stimulus can no longer prevent the cell's predetermined course to death. This point-of-no-return remains a hypothetical, empirically defined entity (the point from which cells cannot recover), which lacks a clearcut biochemical definition. The final dismantling stage then contributes to the disposal/ degradation of the cell corpse. The importance of this final stage especially in caspase-dependent apoptosis is emphasized by the existence of specialized pathways for dismantling 


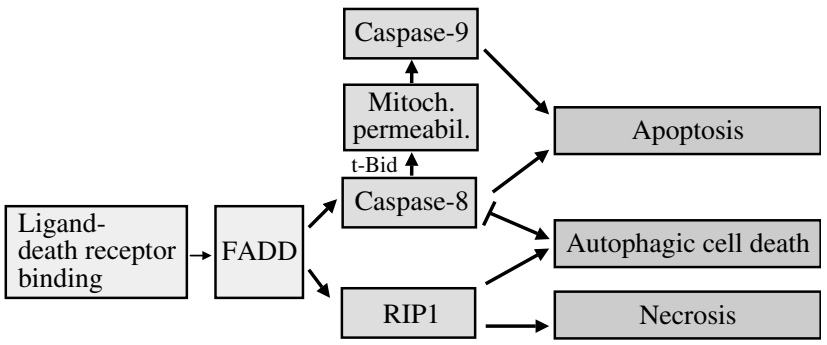

Signaling stage $\rightarrow$ Effector stage $\rightarrow$ Dismantling stage

Figure 1 Death receptor-mediated activation of multiple cell death types. Upon engagement by their ligands, cell death receptors such as TNFR or CD95/Fas, transduce a signal that may involve the clustering of FADD. This frequently leads to apoptosis through activation of caspase-8. Upon caspase inhibition or in certain cell types, another pathway, which relies on RIP1, can lead to necrosis. In yet other circumstances, inhibition of caspase-8 can trigger autophagic cell death through RIP1. Different death receptors may vary in their mode of connexion to caspase-8 and RIP1. ${ }^{73,74}$. For this and other figures, see main text for other references and details

cell structures, such as the pathways leading to DNA fragmentation ${ }^{12}$ or to cell surface blebbing. ${ }^{13}$ At least in the animal kingdom, this systematic and structure-specific dismantling, moreover followed by rapid engulfment of dying cells, ${ }^{14,15}$ strongly suggests that there is a strict requirement for swift and complete disappearance of dead cells. Autophagy may ensure dismantling for some cell deaths both inside and outside of the animal kingdom, and in the latter kingdom recruitment of caspases as an extra tool for dismantling may have represented a further evolutionary advantage. The selective benefit of efficient dismantling will be considered again below, when discussing the possible phylogeny of cell death types.

\section{Inhibition/Replacement of Cell Death Types}

In some model organisms (such as Caenorhabditis elegans), inactivation of cell death-associated hydrolases (e.g. CED-3, the $C$. elegans ortholog of mammalian caspase-3 and -9) or their activators (e.g. CED-4, the $C$. elegans ortholog of mammalian Apaf-1) can abolish somatic cell death during development. ${ }^{16}$ However, in many other examples, the removal of such molecules does not prevent cell death as such and rather suppresses the manifestation of a particular cell death mechanism, revealing another one. Cells still die, but differently.

An example of such a situation is the death receptor pathway, in which ligand engagement of death receptors (for instance TNF-R1 or CD95/Fas) can trigger distinct lethal mechanisms. Engagement of the death receptor leads to the recruitment of the adaptor protein FADD, which in turn can recruit and activate caspase- 8 (then leading to apoptosis) or RIP1 (Figure 1). Depending on cells, conditions and stimuli, inhibition of caspase-8 can truly interrupt lethal signaling, favor a switch from apoptotic to necrotic cell death, ${ }^{17-19}$ which depends on RIP1, 20,21 or induce (again RIP1-dependent) autophagic cell death. ${ }^{22}$ Caspase inhibition has also been shown to lead to a switch from apoptosis to necrosis in, for example, thymocytes responding to DNA damage ${ }^{23}$ or from apoptosis to autophagic cell death in, for example, growth factor-deprived neurons. ${ }^{24}$ Furthermore, conditions that normally induce apoptosis through cellular stress (e.g. DNA damage or inhibition of protein kinases with staurosporine) induce necrosis when ATP supply is limited. ${ }^{11}$ Downmodulation of the antiapoptotic protein $\mathrm{Bcl}-2^{25}$ or upregulation of the proapoptotic $\mathrm{Bcl}-2$ homolog $\mathrm{BNIP}^{26}$ can induce death accompanied by autophagic vacuolization. In mouse embryonic fibroblasts lacking the proapoptotic proteins Bax and Bak, alkylating DNA damage induces a necrotic type of cell death that relies on ATP depletion, ${ }^{27}$ and etoposide induces an autophagic type of cell death dependent on autophagy proteins ATG5 and beclin, ${ }^{28}$ while both types of damage induce apoptosis in Bax- or Bak-sufficient control cells. Conversely, inhibition of macroautophagy can provoke caspase-dependent apoptosis in starving HeLa cells. ${ }^{29}$

Another example is provided by mice in which the ced-3 or ced-4 orthologs (casp3, casp9, apaf1) have been knocked out. Such mice are deficient in a main caspase activation pathway, yet show relatively minor developmental defects, mostly forebrain hyperplasia. ${ }^{30-33}$ Thus, most of the cell death associated with normal development in wild-type mice occurs also in the mutant mice, either through alternative caspase activation or through caspase-independent nonapoptotic cell death. Indeed, in apaf1 $1^{-1-}$ mice, interdigital cell death occurs through caspase-independent necrosis rather than through apoptosis $^{34}$ (Figure 2). Similarly, an histone deacetylase inhibitor triggers autophagic cell death in mouse embryonic
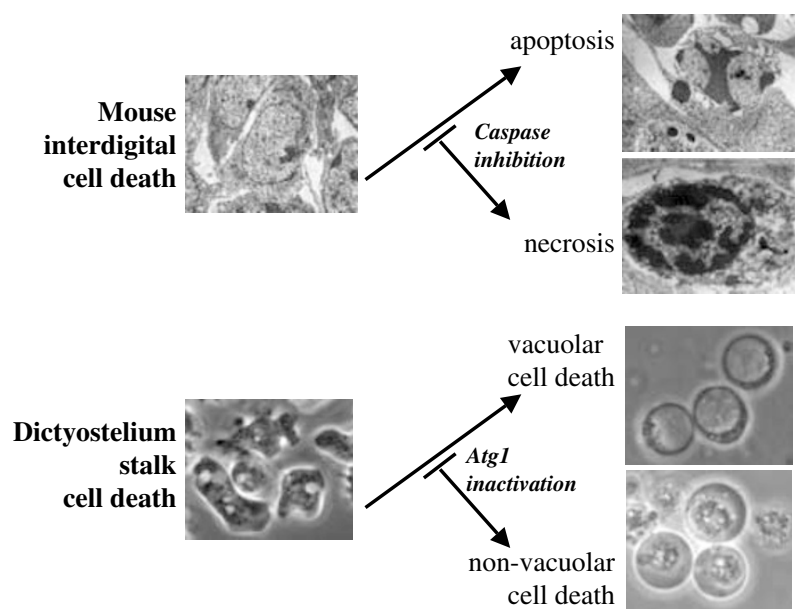

Figure 2 Two examples of inhibition/replacement of cell death types in development. The upper panel shows electron microscopy pictures of dying interdigital cells in a mouse embryo. Caspase inhibition led to a shift from apoptotic (marked apoptotic condensation, also in apoptotic bodies engulfed in adjacent cells) to necrotic (one necrotic cell is shown, with more disperse chromatin condensation and dilated mitochondria) cell death. ${ }^{34}$ The lower panel shows light microscopy pictures of dying Dictyostelium cells, in an in vitro model mimicking development in this protist. Autophagy inhibition led to a shift from vacuolar (three cells are shown, each with a very large vacuole occupying most of the cell volume) to nonvacuolar (amid debris, three cells are shown, each with central organelle clustering and wih no vacuole) cell death. ${ }^{42}$ In either example, distinct types of cell death can be triggered by the same developmental signal. Note that it is not formally demonstrated whether it is only the dismantling mechanisms, or also the effector mechanisms, which are affected by the experimental manipulation 
fibroblasts from apaf1/- mice, instead of apoptosis in wild-type control cells. ${ }^{35}$ In some nonforebrain regions of the nervous system of $\mathrm{casp}^{-/-}$and $\mathrm{casp}^{-/-}$mice, the frequency and localization of dying cells was undistinguishable from wildtype controls, but the type of cell death was nonapoptotic, with marked vacuolization. ${ }^{36}$ Similar findings were made for motoneurons in chick embryos upon caspase inhibition. ${ }^{37}$ The differential behavior of forebrain and nonforebrain neurons in the mutant mice discussed above indicates that distinct cell types (within the same species and the same organ) can house distinct potential cell death mechanisms. Similarly, in some tissues of adult $C$. elegans necrotic cell death can occur, ${ }^{38}$ suggesting that the nonredundancy of apoptotic developmental cell death in this organism, as analyzed by Horvitz et $\mathrm{al}^{39}$ is due to tissue-specific expression of only one of several possible cell death mechanisms. In other words, cell differentiation can reduce the spectrum of cell death mechanisms available to a given species.

Also in a developmental context, but now in a protist model, Dictyostelium discoideum cells can be induced to die in vitro through starvation and addition of a differentiation factor called DIF, thus mimicking developmental induction of stalk cell death in vivo. Dying cells exhibit autophagy and massive vacuolization. ${ }^{40,41}$ Disruption of the Atg1 gene (impairing autophagy) suppresses vacuolization but not DIF-induced cell death. Atg1 mutant cells exhibit a distinct nonvacuolar morphotype when they die upon addition of DIF. Thus, impairing autophagy causes a switch from vacuolar to nonvacuolar DIF-induced cell death ${ }^{42}$ (Figure 2). With some reserve due to uncertainties as to vacuolar cell death, ${ }^{42}$ these results show that inhibition/replacement of cell death types can also occur outside the animal kingdom.

In animals, distinct mechanisms might intersect through shared molecules such as Beclin-1/Atg-6 (which interacts with the apoptosis regulator $\mathrm{Bcl}-2$, yet is also essential for autophagy ${ }^{22}$ ) or DAP kinase (a positive regulator of autophagy and apoptotic blebbing ${ }^{43}$ ) or exert unidirectional inhibition of one on the other, as has been shown for proapoptotic caspases, which can repress necrosis ${ }^{44}$ or antiapoptotic $\mathrm{Bcl}-\mathrm{XL}$ which can facilitate autophagic cell death. ${ }^{28}$ The latter interdeath mechanism inhibition, for which as yet there are only few examples, may well account for the masking of one mechanism by another in cells undergoing death.

In conclusion, different cell death types can substitute for each other in experimental and perhaps as discussed below in pathological circumstances. Apoptosis can be replaced by necrotic or autophagic cell death, while the latter can be replaced by apoptotic or necrotic cell death. Thus, there is no general evidence in favor of a hierarchical relationship between apoptosis and autophagic cell death. In contrast, there are relatively few reports on experimental interventions shifting necrosis to apoptosis or autophagic cell death. ${ }^{21,45}$ Beyond the fact that the poor knowledge of the molecular mechanism governing necrosis makes it difficult to inhibit this type of death, this might point to a stratification of cell death mechanisms, perhaps reflecting their order of emergence in evolution. Apoptosis and autophagy might serve as more elaborate 'functionally dominant' mechanisms, which, when inhibited, may reveal a more primitive mode of cell death, necrosis.

\section{Hypothetical Evolution of Cell Death Mechanisms}

How did the several cell death mechanisms emerge in evolution? We hypothesize that an ancestral cell death mechanism was overlayered with added mechanisms. A popular, plausible ${ }^{46}$ yet speculative ${ }^{47}$ scenario states that the ancestral cell death mechanism (which may have resembled 'necrosis') might stem from the intrusion of the bacterial precursor of the mitochondrion (the endosymbiont) into the precursor of the eukaryotic cell. In favor of the mitochondrial involvement in the emergence of cell death, it appears that some of the mitochondrial proteins which can be involved in mammalian cell death (such as AIF, cytochrome $c$, and the serine protease $\mathrm{HtrA} / \mathrm{Omi}$ ) and in yeast cell death (AIF1) ${ }^{48}$ are present in the genome of bacterial ancestors of mitochondria, ${ }^{46,49}$ as are the evolutionary ancestors of caspases, the meta-caspases. ${ }^{46}$

As additions to such an ancestral cell death mechanism, while autophagy emerged in evolution before apoptosis and possibly initially only as a restorative pathway, both apoptosis and autophagy might have entered cell death pathways at the dismantling stage, in order to facilitate the disposal of cell corpses (Figure 3). We inferred above the probably important selective advantage of getting rid of the cell corpse, at least in the animal kingdom, as judged from the several sophisticated specialized pathways at play at the dismantling stage reinforced by further disposal of the dead cell corpse through an equally sophisticated engulfment process. Rapid degradation/clearance of dying cells may be beneficial through minimization of energy expenditure by dying cells, rapid recycling of building blocks from dead to live cells, quick liberation of the space occupied by corpses, and in vertebrates prevention of autoimmune responses. Thus, evolution may have favored the recruitment of elaborate dismantling mechanisms. Autophagy may ensure dismantling for some cell deaths in all eukaryotic kingdoms, while in the animal kingdom recruitment of caspases may have represented a further evolutionary advantage. These additional mechanisms (apoptotic caspase activation and autophagy) then may have extended their role from their original function dismantling - to a participation in cell death effector mechanisms and thus acquired 'autonomy' and sometimes even 'exclusivity', in some species or cell types. Autonomy may have been achieved by coupling a lethal signal (or absence of a survival signal) and stress sensors to the immediate activation of caspases (e.g. CD95/Fas to caspase-8, nuclear DNA damage to caspase-2, ER stress to caspase-12), upstream of the phylogenetically ancient mitochondrial checkpoint. Exclusivity would then result from the suppression of the original checkpoint as well as that of all parallel pathways of lethal signal transduction (Figure 3). One example for an advanced degree of autonomisation is provided by a restricted fraction of cell types ('type-1 cells') in which CD95 ligation can result in massive caspase activation, overriding the mitochondrial checkpoint, ${ }^{50}$ although such cells still can undergo mitochondrion-dependent apoptosis in response to DNA damage. An example of possible extension even to the signaling stage for the role of caspases is provided by the caspase-induced activation of 

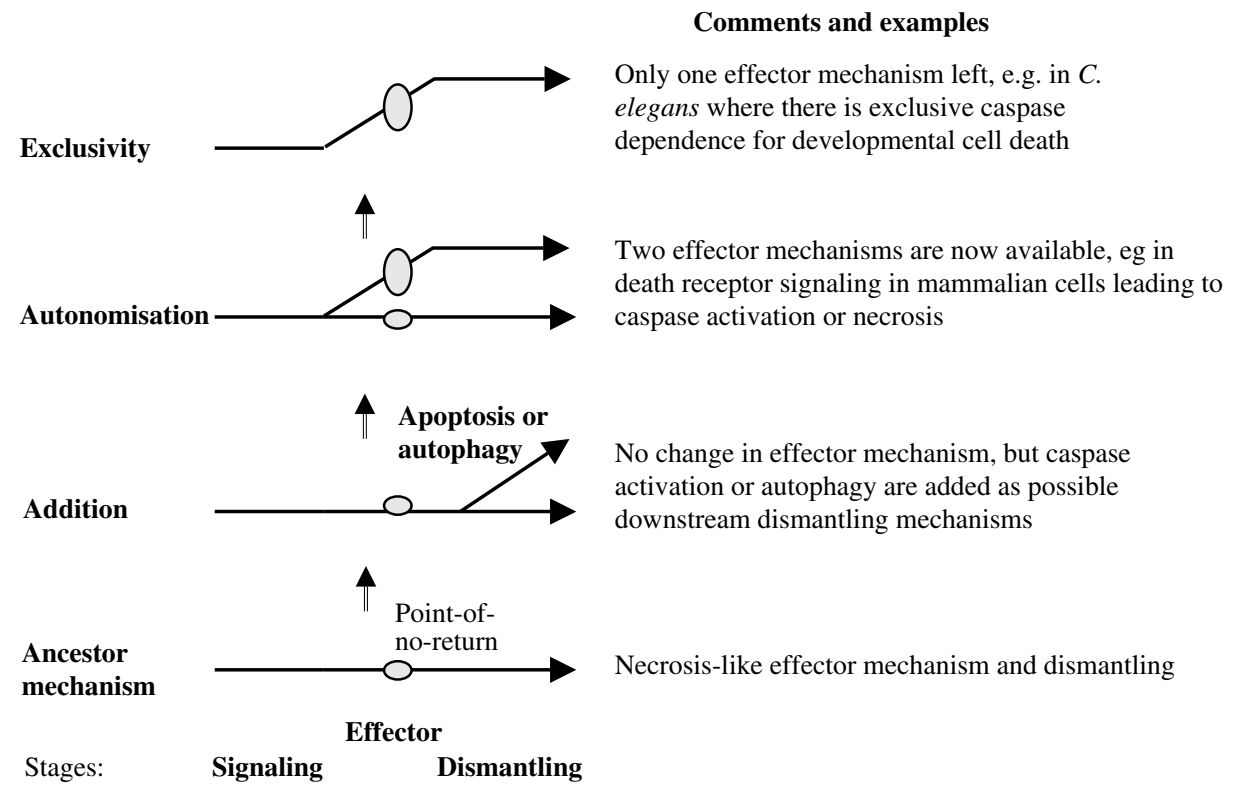

Figure 3 A schematic hypothetical representation of cell death mechanism evolution. From lower to upper panels, initially the ancestral mechanism includes a point-ofno-return at the effector stage, which may have a mitochondrial basis as described in the main text, and may correspond to a necrotic type of cell death. At the next step, while the point-of-no-return would still be 'necrotic', addition at the dismantling stage of autophagic (in several eukaryotic kingdoms) or apoptotic (only in the animal kingdom in its classical caspase-dependent version) elements would allow necrotic, apoptotic or autophagic cell death types to develop. Further autonomization of apoptosis or autophagy would confer effector activity to them. The upper and extreme situation would occur when the ancestral mechanism is genetically lost in the whole organism or epigenetically suppressed in some tissues, leaving full effector activity in an exclusive way to either apoptosis or autophagy. The overall result is the replacement of the ancestral effector mechanism by the incoming mechanism originally operative in dismantling only

some dependence receptors. ${ }^{51}$ An example of exclusivity is developmental cell death of somatic cells in C. elegans, an apoptotic cell death whose inhibition led to no death rather than to an alternative type of cell death. ${ }^{39}$

These and other data indicate that caspases can either participate in the dismantling phase only, or in both the effector and the dismantling phases. Although it is often assumed that autophagy can participate in the effector phase of cell death (at or around the point-of-no-return), thus far there is no definitive proof that genetic ablation of Atg genes (which are required for autophagy) can prevent cell death, in spite of suggestive evidence that autophagy is indeed involved in the lethal process. ${ }^{10,52-54}$ Our provisional conclusion on this point is that caspases may participate in both the effector and the dismantling phases of apoptosis, while for autophagy only a dismantling role has been formally demonstrated. More generally, the hypothesis above predicts that in any given cell the multiplicity of cell death pathways may be greater at the dismantling than at the effector stage. This is not only of academic interest. Whether a cell that can show two types of death (and thus houses two mechanisms of dismantling) possesses only a single or two effector mechanism(s) is of obvious practical importance. We often do not know enough as yet to clearly identify dismantling mechanisms, let alone effector mechanisms.

Thus, cell death mechanisms emerging later in evolution would mask more ancient mechanisms, which would however persist, not only as phylogenetic relics but also as back-up mechanisms as further discussed below. Altogether, this scenario of cell death evolution would account for the widely observed redundancy of cell death types, implying that suppression of one particular type of cell death (for instance apoptosis) may often cause the manifestation of another type of death (for instance autophagic or necrotic cell death).

\section{Pathophysiological Implications}

The redundancy of cell death mechanisms has wide-reaching pathophysiological and medical implications. The redundancy of effector mechanisms (as opposed to dismantling mechanisms) has important consequences for therapeutic inhibition of unwarranted cell death, while redundancy of dismantling mechanisms constitutes a challenge for the diagnostic detection of cell death.

It has often been tacitly assumed that mammalian cell death is mostly mediated by apoptosis. This consensus stems, in part, from the pioneering description of apoptosis as a defined cell death modality, ${ }^{1}$ as well as from the early studies on $C$. elegans somatic cell death, ${ }^{16}$ which, while elegantly and importantly demonstrating genetic control of apoptotic cell death, may have led researchers to apprehend and characterize caspase-dependent apoptosis while neglecting other cell death modalities. This bias was reinforced by wide spread identification of (apoptotically) dying cells with the TUNEL staining, a method which only detects a largely caspasedependent type of DNA fragmentation, ${ }^{55}$ and hence ignores nonapoptotic events.

There are indeed arguments in favor of a relatively high incidence of nonapoptotic cell deaths in vivo, especially in 
conditions in which key apoptotic effectors are inhibited. As stated above, genetic inactivation or pharmacological inhibition of caspases may have only limited effects on developmental cell death. Knockout studies often revealed unexpected effects of caspases in differentiation and activation of particular cell types, yet did not reveal general developmental cell death impairment affecting multiple cell types. ${ }^{56}$ Similarly, pharmacological caspase inhibition did not always rescue cells from pathological death, for instance in the context of lethal TNF-induced shock, ${ }^{57}$ or of myocardial infarction and neurodegeneration. ${ }^{58}$ In heart failure, cardiomyocytes show autophagic rather than apoptotic cell death. ${ }^{59}$ One of the few diseases in which caspase inhibitors may yield convincing preclinical effects is septic shock, ${ }^{60}$ which involves the contribution of caspases, not only as cellular demolition enzymes but also for the biosynthesis of proinflammatory cytokines. Thus, although caspase inhibition can successfully prevent the phenotypic manifestation of apoptosis, it often does not prevent cell death, which is likely to be executed through different mechanisms (including apoptosis-like cell death, autophagy and necrosis) $)^{5,23,24,34,61}$ and perhaps through phagocytic recognition and destruction. ${ }^{62,63}$ As mentioned above, it is possible that different cell types present in the same organism differ in their potential to execute cell death through distinct mechanisms. In this context, the tissue distribution of various effector mechanisms and of their redundancy may warrant a more detailed exploration, since it would determine the success of therapeutic approaches to control cell death.

In the face of the multiplicity of cell death types, how should cell death be detected? Apoptosis is commonly detected by techniques that measure postcaspase events, such as the cleavage of caspase substrates or the CAD-mediated degradation of nuclear DNA. As discussed above, nonapoptotic cell death mechanisms may play a significant role in mammals in developmental situations. Apoptosis may also be inhibited by pathogens (for instance by virus-encoded caspase inhibitors), in which case other lethal mechanisms may take over. ${ }^{64,65}$ This emphasizes the need for tools able to detect non-apoptotic cell death in pathological tissues. Unfortunately, methods for the detection of autophagy applicable to whole animals are based on transgenics. ${ }^{66} \mathrm{~A}$ histological method for the visualization of apoptosis-like cell death (which detects AIF in the nucleus) ${ }^{67}$ has still to be validated in vivo. Optimal identification of necrotic cells in vivo would require electron microscopy, which is impractical for routine diagnostics. Reliable and convenient markers for easy in situ detection of nonapoptotic cell deaths are badly needed, yet elusive.

In the face of functional redundancy of cell death mechanisms, how can cell death be prevented? Attempts to reduce unwarranted cell death in human medicine must take into account the fact that therapeutic inhibition of a given mechanism may not necessarily inhibit cell loss and may rather unmask another mechanism of cell death. Serial unmasking is conceivable, whereby a cell usually dying from apoptosis might shift to autophagic death when caspases are inhibited and to necrosis when, in addition, Atg genes are inhibited. Caspase inhibition must either be combined with additional inhibitors (for instance of autophagy) to rescue cells from death ${ }^{22,24}$ or cell rescue must be attempted by targeting upstream events, perhaps in particular mitochondrial events. Thus, gene therapies and pharmacological agents capable of suppressing the cell death-associated mitochondrial membrane permeabilization have been shown to have a broad cytoprotective effect, in preclinical ${ }^{68}$ as well as clinical studies. ${ }^{69}$ This emphasizes the probable need to inactivate the putative ancestral, yet elusive cell death mechanism for cytoprotection, and therefore to direct further efforts towards a detailed molecular definition of this process. On the other hand, the reciprocal attempts at trying to increase cell death, in particular of cancer cells, are less affected by, and may even sometimes benefit from, the redundancy of mechanisms, provided care is taken to keep cell death selective. In certain circumstances, it may be even useful to shift from one cell death pathway to another, for instance by inhibiting apoptosis of cancer cells, because necrotic tumor cells may elicit a productive anticancer immune response. ${ }^{70}$

Any given cell contains a specific death-governing network associating different effector and/or dismantling mechanisms. It is not a given mechanism, but all possible effector elements of this network that should be inhibited if one wishes a given cell to survive. A major task ahead, at least for the less well known nonapoptotic types of cell death, will be to shift from the identification and study of cell death types, which reflect dismantling events, to an understanding of effector mechanisms. A second task will be to clarify for each cell the degree of multiplicity of these effector mechanisms. These include nonapoptotic cell death mechanisms, further analyses of which are therefore urgent. One approach to this end might be to enlist nonconventional model organisms, ${ }^{71}$ especially outside of the animal kingdom, where experimental accessibility of nonapoptotic cell death might be easier and molecular redundancy might be less than in the usual animal models. The assumption here is that some cell death mechanisms may be conserved across kingdoms, which is perhaps not unreasonable considering the degree of phylogenetic conservation of other major cell functions. In parallel, a search for the molecular bases of nonapoptotic cell death mechanisms in the usual animal models might greatly benefit from novel approaches such as $\mathrm{RNAi}^{72}$ and proteomics.

\section{Acknowledgements}

We thank Philippe Dessen (IGR) and Jonathan Ewbank (CIML) for critical discussions. This work was supported by grants from Association pour la Recherche contre le Cancer, Ministère de la Recherche et de la Technologie, Ligue Nationale contre le Cancer and the European Commission (FP6, TransDeath LSHG-CT-2004-511983).

\section{References}

1. Kerr JFR, Wyllie AH and Currie AR (1972) Apoptosis: a basic biological phenomenon with wide-ranging implications in tissue kinetics. Br. J. Cancer 26: 239-257

2. Clarke PGH and Clarke S (1995) Historic apoptosis. Nature 378: 230

3. Majno $G$ and Joris I (1995) Apoptosis, oncosis, and necrosis. An overview of cell death. Am. J. Pathol. 146: 3-15 
4. Bursch W (2001) The autophagosomal-lysosomal compartment in programmed cell death. Cell Death Differ. 8: 569-581

5. Leist $M$ and Jaattela $M$ (2001) Four deaths and a funeral: from caspases to alternative mechanisms. Nat. Rev. Mol. Cell Biol. 2: 589-598

6. Sperandio S, Poksay K, De Belle I, Lafuente MJ, Liu B, Nasir J and Bredesen DE (2004) Paraptosis: mediation by MAP kinases and inhibition by AIP-1/Alix. Cell Death Differ. 11: 1066-1075

7. Lemasters JJ (1999) V. Necrapoptosis and the mitochondrial permeability transition: shared pathways to necrosis and apoptosis. Am. J. Physiol. 276 (1 Part 1): G1-G6

8. Lee CY and Baehrecke EH. (2001) Steroid regulation of autophagic programmed cell death during development. Development 128: 1443-1455

9. Martin DN and Baehrecke EH (2004) Caspases function in autophagic programmed cell death in Drosophila. Development. 131: 275-284

10. Levine B and Klionsky DJ (2004) Development by self-digestion: molecular mechanisms and biological functions of autophagy. Dev. Cell. 6: 463-477

11. Leist M, Single B, Castoldi AF, Kühnle $S$ and Nicotera $P$ (1997) Intracellular adenosine triphosphate (ATP) concentration: a switch in the decision between apoptosis and necrosis. J. Exp. Med. 185: 1481-1486

12. Enari M, Sakahira H, Yokoyama H, Okawa K, Iwamatsu A and Nagata S (1998) A caspase-activated DNase that degrades DNA during apoptosis, and its inhibitor ICAD. Nature 391: 43-50

13. Sebbagh M, Renvoize C, Hamelin J, Riche N, Bertoglio J and Breard J (2001) Caspase-3-mediated cleavage of ROCK I induces MLC phosphorylation and apoptotic membrane blebbing. Nat. Cell Biol. 3: 346-352

14. Savill J, Dransfield I, Gregory C and Haslett C (2002) A blast from the past: clearance of apoptotic cells regulates immune responses. Nat. Rev. Immunol. 2: $965-975$

15. Reddien PW and Horvitz HR (2004) The engulfment process of programmed cell death in Caenorhabditis elegans. Annu. Rev. Cell Dev. Biol. 20: 193-221

16. Ellis HM and Horvitz HR (1986) Genetic control of programmed cell death in the nematode C. elegans. Cell. 44: 817-829

17. Vercammen D, Brouckaert G, Denecker G, Van de Craen M, Declercq W, Fiers W and Vandenabeele P (1998) Dual signaling of the Fas receptor: initiation of both apoptotic and necrotic cell death pathways. J. Exp. Med. 188: 919-930

18. Kawahara A, Ohsawa Y, Matsumura H, Uchiyama Y and Nagata S (1998) Caspase-independent cell killing by fas-associated protein with death domain J. Cell Biol. 143: 1353-1360

19. Matsumura $H$, Shimizu $Y$, Ohsawa $Y$, Kawahara A, Uchiyama $Y$ and Nagata $S$ (2000) Necrotic death pathway in fas receptor signaling. J. Cell Biol. 151: 12471256

20. Holler N, Zaru R, Micheau O, Thome M, Attinge A, Valitutti S, Bodmer JL, Schneider P, Seed B and Tschopp J (2000) Fas triggers an alternative, caspase-8-independent cell death pathway using the kinase RIP as effector molecule. Nat. Immunol. 1: 489-495

21. Van den Berghe T, Van Loo G, Saelens X, Van Gurp M, Brouckaert G, Kalai M, Declercq W and Vandenabeele P (2004) Differential signaling to apoptotic and necrotic cell death by Fas-associated death domain protein FADD. J. Biol. Chem. 279: 7925-7933

22. Yu L, Alva A, Su H, Dutt P, Freundt E, Welsh S, Baehrecke EH and Lenardo MJ (2004) Regulation of an ATG7-beclin 1 program of autophagic cell death by caspase-8. Science 304: 1500-1502

23. Hirsch T, Marchetti P, Susin SA, Dallaporta B, Zamzami N, Marzo I, Geuskens $M$ and Kroemer $G$ (1997) The apoptosis-necrosis paradox. Apoptogenic proteases activated after mitochondrial permeability transition determine the mode of cell death. Oncogene 15: 1573-1582

24. Xue L, Fletcher GC and Tolkovsky AM (2001) Mitochondria are selectively eliminated from eukaryotic cells after blockade of caspases during apoptosis Curr. Biol. 6: 361-365

25. Saeki K, Yuo A, Okuma E, Yazaki Y, Susin SA, Kroemer G and Takaku F (2000) Bcl-2 down-regulation causes autophagy in a caspase-independent manner in human leukemic HL60 cells. Cell Death Differ. 7: 1263-1269

26. Daido S, Kanzawa T, Yamamoto A, Takeuchi H, Kondo Y and Kondo S (2004) Pivotal role of the cell death factor BNIP3 in ceramide-induced autophagic cell death in malignant glioma cells. Cancer Res. 64: 4286-4293

27. Zong WX, Ditsworth D, Bauer DE, Wang ZQ and Thompson CB (2004) Alkylating DNA damage stimulates a regulated form of necrotic cell death. Genes Dev. 18: 1272-1282
28. Shimizu S, Kanaseki T, Mizushima N, Mizuta T, Arakawa-Kobayashi S, Thompson CB, Korsmeyer SJ and Tsujimoto Y (2004) A role of Bcl-2 family of proteins in non-apoptotic programmed cell death dependent on autophagy genes. Nat. Cell Biol. 6: 1221-1228

29. Boya P, Gonzalez-Polo R-A, Casares N, Perfettini J-L, Dessen P, Larochette N, Metivier D, Meley D, Souquere S, Pierron G, Ohsumi $Y$, Codogno $P$ and Kroemer $G$ (2005) Inhibition of macroautophagy triggers apoptosis. Mol. Cell. Biol. 25: 1025-1040

30. Cecconi F, Alvarez-Bolado G, Meyer Bl, Roth KA and Gruss P (1998) Apaf1 (CED-4 homolog) regulates programmed cell death in mammalian development. Cell 94: 727-737

31. Yoshida H, Kong YY, Yoshida R, Elia AJ, Hakem A, Hakem R, Penninger JM and Mak TW (1998) Apaf1 is required for mitochondrial pathways of apoptosis and brain development. Cell 94: 739-750

32. Kuida K, Haydar TF, Kuan CY, Gu Y, Taya C, Karasuyama H, Su MS, Rakic P and Flavell RA (1998) Reduced apoptosis and cytochrome c-mediated caspase activation in mice lacking caspase 9. Cell 94: 325-337

33. Kuida K, Zheng TS, Na SQ, Kuan CY, Yang D, Karasuyama H, Rakic P and Flavell RA (1996) Decreased apoptosis in the brain and premature lethality in CPP32-deficient mice. Nature 384: 368-372

34. Chautan M, Chazal G, Cecconi F, Gruss P and Golstein P (1999) Interdigital cell death can occur through a necrotic and caspase-independent pathway. Curr. Biol. 9: 967-970

35. Shao Y, Gao Z, Marks PA and Jiang X (2004) Apoptotic and autophagic cell death induced by histone deacetylase inhibitors. Proc. Natl. Acad. Sci. USA 101: 18030-18035

36. Oppenheim RW, Flavell RA, Vinsant S, Prevette D, Kuan CY and Rakic P (2001) Programmed cell death of developing mammalian neurons after genetic deletion of caspases. J. Neurosci. 21: 4752-4760

37. Yaginuma H, Shiraiwa N, Shimada T, Nishiyama K, Hong J, Wang S, Momoi T, Uchiyama $Y$ and Oppenheim RW (2001) Caspase activity is involved in, but is dispensable for, early motoneuron death in the chick embryo cervical spinal cord. Mol. Cell Neurosci. 18: 168-182

38. Xu K, Tavernarakis N and Driscoll M (2001) Necrotic cell death in C. elegans requires the function of calreticulin and regulators of $\mathrm{Ca}(2+)$ release from the endoplasmic reticulum. Neuron 31: 957-971

39. Horvitz HR, Shaham S and Hengartner MO (1994) The genetics of programmed cell death in the nematode Caenorhabditis elegans. Cold Spring Harbor Symp. Quant. Biol. 59: 377-386

40. Cornillon S, Foa C, Davoust J, Buonavista N, Gross JD and Golstein P (1994) Programmed cell death in Dictyostelium. J. Cell Sci. 107: 2691-2704

41. Levraud J-P, Adam M, Luciani M-F, De Chastellier C, Blanton RL and Golstein $P$ (2003) Dictyostelium cell death: early emergence and demise of highly polarized paddle cells. J. Cell Biol. 160: 1105-1114

42. Kosta A, Roisin-Bouffay C, Luciani MF, Otto GP, Kessin RH and Golstein P (2004) Autophagy gene disruption reveals a non-vacuolar cell death pathway in Dictyostelium. J. Biol. Chem. 279: 48404-48409

43. Inbal B, Bialik S, Sabanay I, Shani G and Kimchi A (2002) DAP kinase and DRP-1 mediate membrane blebbing and the formation of autophagic vesicles during programmed cell death. J. Cell Biol. 157: 455-468

44. Vercammen D, Beyaert R, Denecker G, Goossens V, Van Loo G, Declercq W, Grooten J, Fiers W and Vandenabeele P (1998) Inhibition of caspases increases the sensitivity of L929 cells to necrosis mediated by tumor necrosis factor. J. Exp. Med. 187: 1477-1485

45. Kim JS, Qian T and Lemasters JJ (2003) Mitochondrial permeability transition in the switch from necrotic to apoptotic cell death in ischemic rat hepatocytes. Gastroenterology. 124: 494-503

46. Koonin EV and Aravind L (2002) Origin and evolution of eukaryotic apoptosis: the bacterial connection. Cell Death Differ. 9: 394-404

47. Ameisen JC (2002) On the origin, evolution, and nature of programmed cell death: a timeline of four billion years. Cell Death Differ. 9: 367-393

48. Wissing S, Ludovico P, Herker E, Büttner S, Engelhardt SM, Decker T, Link A, Proksch A, Rodrigues F, Corte-Real M, Fröhlich K-U, Manns J, Candé C, Sigrist SJ, Kroemer $\mathrm{G}$ and Madeo F (2004) An AIF orthologue regulates apoptosis in yeast. J. Cell Biol. 166: 969-974

49. Cande C, Cecconi F, Dessen P and Kroemer G (2002) Apoptosis-inducing factor (AIF): key to the conserved caspase- independent pathways of cell death? J. Cell Sci. 115 (Part 24): 4727-4734 
50. Scaffidi C, Fulda S, Srinivasan A, Friesen C, Li F, Tomaselli KJ, Debatin KM Krammer PH and Peter ME (1998) Two CD95 (APO-1/Fas) signaling pathways. EMBO J. 17: 1675-1687

51. Mehlen $P$ and Thibert C (2004) Dependence receptors: between life and death Cell Mol. Life Sci. 61: 1854-1866

52. Elmore SP, Qian T, Grissom SF and Lemasters JJ (2001) The mitochondrial permeability transition initiates autophagy in rat hepatocytes. FASEB J. 15: 2286-2287

53. Tolkovsky AM, Xue L, Fletcher GC and Borutaite V (2002) Mitochondrial disappearance from cells: a clue to the role of autophagy in programmed cell death and disease? Biochimie 84: 233-240

54. Kissova II, Deffieu M, Manon S and Camougrand N (2004) Uth1p is involved in the autophagic degradation of mitochondria. J. Biol. Chem. 279: 39068-39074

55. Gavrieli Y, Sherman $Y$ and Ben-Sasson SA (1992) Identification of programmed cell death in situ via specific labeling of nuclear DNA fragmentation. J. Cell Biol. 119: 493-501

56. Garrido C and Kroemer G (2004) Life's smile, death's grin: vital functions of apoptosis-executing proteins. Curr. Opin. Cell Biol. 16: 639-646

57. Cauwels A, Janssen B, Waeytens A, Cuvelier C and Brouckaert P (2003) Caspase inhibition causes hyperacute tumor necrosis factor-induced shock via oxidative stress and phospholipase A2. Nat. Immunol. 4: 387-393

58. Mattson MP and Kroemer G (2003) Mitochondria in cell death: novel targets for neuroprotection and cardioprotection. Trends Mol. Med. 9: 196-205

59. Knaapen MW, Davies MJ, De Bie M, Haven AJ, Martinet W and Kockx MM (2001) Apoptotic versus autophagic cell death in heart failure. Cardiovasc. Res. 51: 304-312

60. Hotchkiss RS, Chang K, Swanson PE, Tinsley KW, Hui JJ, Klender P, Xanthoudakis S, Roy S, Black C, Grimm E, Aspiotis R, Han Y, Nicholson DW and Karl IE (2000) Caspase inhibitors improve survival in sepsis: a critical role of the lymphocyte. Nat. Immunol. 1: 496-501

61. Jaattela M and Tschopp J (2003) Caspase-independent cell death in T lymphocytes. Nat. Immunol. 4: 416-423

62. Hoeppner DJ, Hengartner MO and Schnabel R (2001) Engulfment genes cooperate with ced-3 to promote cell death in Caenorhabditis elegans. Nature. 412: 202-206
63. Marin-Teva JL, Dusart I, Colin C, Gervais A, van Rooijen N and Mallat M (2004) Microglia promote the death of developing Purkinje cells. Neuron 41: 535-547

64. Ekert PG, Silke J and Vaux DL (1999) Caspase inhibitors. Cell Death Differ. 6 : 1081-1086

65. Griffin DE and Hardwick JM (1999) Perspective: virus infections and the death of neurons. Trends Microbiol. 7: 155-160

66. Mizushima N, Yamamoto A, Matsui M, Yoshimori T and Ohsumi Y (2004) In vivo analysis of autophagy in response to nutrient starvation using transgenic mice expressing a fluorescent autophagosome marker. Mol. Biol. Cell. 15: $1101-1111$

67. Zhu C, Quu L, Wang X, Hallin U, Cande C, Kroemer G, Hagberg H and Blomgren K (2003) Involvement of apoptosis-inducing factor in neuronal death after hypoxia-ischemia in the neonatal rat brain. J Neurochem. 86: 306-317

68. Green DR and Kroemer G (2004) The pathophysiology of mitochondrial cell death. Science 305: 626-629

69. Stavrovskaya IG, Narayanan MV, Zhang W, Krasnikov BF, Heemskerk J, Young SS, Blass JP, Brown AM, Beal MF, Friedlander RM and Kristal BS (2004) Clinically approved heterocyclics act on a mitochondrial target and reduce stroke-induced pathology. J. Exp. Med. 200: 211-222

70. Schmitt E, Parcellier A, Ghiringhelli F, Casares N, Gurbuxani S, Droin N, Hamai A, Pequignot M, Hammann A, Moutet M, Fromentin A, Kroemer G, Solary E and Garrido C (2004) Increased immunogenicity of colon cancer cells by selective depletion of cytochrome. Cancer Res. 64: 2705-2711

71. Golstein P, Aubry L and Levraud JP (2003) Cell-death alternative model organisms: why and which? Nat. Rev. Mol. Cell Biol. 4: 798-807

72. Hannon GJ and Rossi JJ (2004) Unlocking the potential of the human genome with RNA interference. Nature 431: 371-378

73. Holler N, Zaru R, Micheau O, Thome M, Attinger A, Valitutti S, Bodmer JL, Schneider P, Seed B and Tschopp J (2000) Fas triggers an alternative, caspase-8-independent cell death pathway using the kinase RIP as effector molecule. Nat. Immunol. 1: 489-495

74. Schneider-Brachert W, Tchikov V, Neumeyer J, Jakob M, Winoto-Morbach S, Held-Feindt J, Heinrich M, Merkel O, Ehrenschwender M, Adam D, Mentlein R, Kabelitz D and Schutze S (2004) Compartmentalization of TNF receptor 1 signaling: internalized TNF receptosomes as death signaling vesicles. Immunity 21: 415-428 